Place of confinement of women delivered in England and Wales in 1970 and 1975

\begin{tabular}{|c|c|c|c|}
\hline & & \multicolumn{2}{|c|}{$\begin{array}{l}\text { "of of women } \\
\text { delivered }\end{array}$} \\
\hline & & 1970 & 1975 \\
\hline NHS hospitals & & $84 \cdot 6$ & $95 \cdot 1$ \\
\hline Obstetric departments & $\because$ & 66.7 & $78 \cdot 4$ \\
\hline GP maternity units & $\because \quad \therefore$ & $17 \cdot 8$ & $16 \cdot 3$ \\
\hline In hospitals without & obstetric & $11 \cdot 7$ & $7 \cdot 2$ \\
\hline $\begin{array}{l}\text { departments } \\
\text { In hospitals with }\end{array}$ & obstetrics & $11 \cdot 7$ & $7 \cdot 2$ \\
\hline departments & ... & $6 \cdot 1$ & $9 \cdot 1$ \\
\hline Other departments & . & 0.09 & 0.03 \\
\hline Home . . . . . & $\ldots$ & $13 \cdot 0$ & $1 \cdot 7$ \\
\hline Other place of confinement & $\ldots$ & $2 \cdot 4$ & $: 3 \cdot 2$ \\
\hline All places of confinement & $\therefore$ & 100.0 & 100.0 \\
\hline No of women delivered & & 786586 & 603666 \\
\hline
\end{tabular}

GP unit in 1970 and 1975 (the most recent year for which the relevant HIPE data are available).

The estimates of the percentages of women who were delivered in GP maternity beds of $17.8^{\circ}{ }_{0}$ in 1970 and $16.3^{\circ}{ }_{0}$ in 1975 are somewhat lower than Dr Bull's estimates of $32.6^{\circ}$ " and $22 \cdot 0^{\circ}{ }_{0}{ }^{2}$ respectively. However, Dr Bull's figures must include claims for home confinements, and if these deliveries are added to those in GP maternity beds confinements for which GPs were responsible are estimated to form $30.8^{\circ}{ }_{0}$ of all deliveries in 1970 and $19.5^{\circ}{ }_{0}$ in 1975 , and only marginally lower than Dr Bull's estimates. This supports Dr Bull's assertion that had I been able to single out births in specialist obstetric beds I should have been likely to find their concentration from Tuesdays to Fridays even more exaggerated than it was for all hospital deliveries.

The figures in the table also support $\mathrm{Dr}$ Bull's belief about the decline in deliveries in what he describes as "isolated general practitioner units" and show an increase in the proportion of deliveries in general practitioner beds in hospitals which also have specialist obstetric beds, although it must be added that the percentage of deliveries in "isolated" units rose marginally from $7 \cdot 2^{\circ}$ o in 1975 to $7 \cdot 8 \%$ in 1976.

Alison Macfarlane

National Perinatal Epidemiology

Unit,

Churchill Hospital,

1 Office of Population Censuses and Surveys, Births Statistics, England and $W$ ales 1976, Series FM1, No 3 . London, HMSO, 1978.

\section{Treatment of the restless legs syndrome} with clonazepam

SIR,-Treatment of the restless legs syndrome is usually unavailing, except when the condition is associated with iron deficiency. In the hope that others may also find it helpful I am reporting the successful use of clonazepam in a small open uncontrolled trial. In five patients the symptoms have been abolished or greatly modified as illustrated by the two most severe examples.

A man of 42 had for 14 years experienced this severe discomfort in the legs when trying to relax in the evening. On going to bed the sensations would increase and spread to the arms and shoulders. They could be momentarily relieved by moving the limbs but often he would have to rise from his bed and walk round the house. When the discomfort was particularly severe it would be accompanied by involuntary jerking of the legs, which, according to his wife, would continue for several hours during sleep. Clonazepam $1 \mathrm{mg}$ given an hour before retiring immediately and completely abolished the nocturnal symptoms. Relief has been maintained by continuing this dose without side effects.

A woman of 65 had suffered from restless legs since childhood. Here again the familiar distressing sensations were relieved by movement and were accompanied by nocturnal myoclonus of the legs. Clonazepam $0.5 \mathrm{mg}$ in the evening and again at bedtime brought almost complete relief of the restless legs and abolished the myoclonus. An unexpected benefit was the complete disappearance of an obstinate pain in the right groin that had been present for over 20 years. This had characteristics that might be linked to the restless legs syndrome as it occurred only at night, waking her from sleep and forcing her to get up and walk about, although this did not bring immediate relief.

Both these patients also had nocturnal myoclonus, but clonazepam has also proved successful in the restless legs syndrome unaccompanied by involuntary movement. I am not aware that this action of clonazepam has been previously reported. Churchill Hospital,

W B MatThEWS

\section{Shortening hospital stay for psychiatric} care

SIR,-May I qualify the conclusions reached by Professor S R Hirsch and others (17 February, p 442) from their study on shortening hospital stay for psychiatric patients? It seems to me from their data that when clinicians attempt to reduce duration of stay by an effort of will only a minority of patients are actually affected, which has only a marginal effect on bed occupancy levels. I am assuming that the only new factor in the treatment programme which they evaluated was the effort of will to get patients home earlier, for nothing else is mentioned about clinical methods. Anyway, the main effects were a small difference in mean duration of stay that was not statistically significant, and a reduction in bed occupancy of, I estimate from their data, about $12 \%$. Let me in no way detract from the value of this study, which set out to determine whether significant economies could be made in this way and showed that they could not.

Yes, I should declare a vested interest. We in Edinburgh managed to achieve a substantial reduction in stay for unselected psychiatric admissions only after months of thoughtful and laborious reorganisation of a ward, which involved staff having to learn new skills and deploy their time quite differently.

Peter F Kennedy

Department of Psychiatry,
University of Edinburgh

\section{Hypnosis}

SIR,-Y Your leading article on hypnosis in the NHS (7 October, p 978) implies that resources should be channelled into the training of doctors and dentists in hypnotic techniques, the presupposition being that such techniques have been conclusively shown to be of scientific value. This, I would respectfully point out, is simply not the case, and it is therefore no wonder that most British doctors have declined to take up the option you suggest, especially in view of the possibility that hypnosis may on occasion be harmful. ${ }^{1}$

While a body of clinical-anecdotal accounts do support your thesis, controlled trials show little advantage over placebo techniques-for example, a "hypnosis-producing drug."' Though the subjective experiences may differ in experimental and control groups, ${ }^{3}$ this is not the case with overt responses. People will go out of their way to please the experimenter ${ }^{4}$ in situations testing hypnotic behaviour. Personality differences may certainly be more important than the effects of trance induction. ${ }^{5}$

As long ago as $1930^{6}$ "waking" and "hypnotic" suggestions were shown to be equally instrumental in producing the required response. Thus, in the case of posthypnotic suggestion, posthypnotic behaviour may be elicited only when the subject believes that the hypnotist-subject relationship still exists.? Subjects showing a high "need for deference" will comply with posthypnotic-like suggestions, whether or not they are hypnotised. ${ }^{8}$ Again, "regression to an earlier age" seems to be a phantom, ${ }^{8}$ and perceptual changes supposedly induced by hypnosis are reproducible by waking suggestions. ${ }^{9}$

What about pain? Childbirth and toothache are the classical hypnosis-susceptible ailments. But again there is no convincing evidence ${ }^{1011}$ of an alleviation in physiological responses to such painful stimuli under hypnotically induced analgesia. Natural childbirth patients in one study ${ }^{12}$ did not differ from untrained patients in estimates of pain intensity.

In short, the case for the specific usefulness and wide applicability of hypnosis is not proved. It seems not to be of superior efficacy to simpler techniques.

Department of Psychological Medicine,

Newcastle General Hospital

Newcastle upon Tyne

Waxman, British Medical fournal, 1978, 2,571 .
Glass, L B, and Barber, T X, Journal of Nervous and Mental Diseases, 1961, 132, 539.

Orne, M T, Journal of Abnormal and Social Psychology, 1959, 58, 277

+ Orne, M T, American Psychology, 1962, 17, 776

Barber, T X, fournal of the American Medical Association, 1960, 172, 680.

Patten, E F, Fournal of Abnormal and Social Psychology, 1930, 25, 319.

$1954,49,503$.

Barber, T X, Psychosomatic Medicine, 1962, 24, 286. Costello, C G, Psychology for Psychiatrists, p 121. Oxford, Pergamon, 1966.

Shor, R E, PhD Thesis, Brandeis University, Waltham, Mass.

${ }^{1}$ Barber, T X, Psychosomatic Medicine, 1963, 25, 303.

12, 189.

\section{Evolutions in medicine}

SIR,-May I, in the interests of temporal and numerical accuracy, point out three errors in Dr A G Hocken's lighthearted and amusing "Letter from Dunedin" (3 February, p 324)?

In paragraph 1 , p 325, Dr Hocken mentions a "five-floor clinical services block opened in 1972." This was actually a six-floor building opened in August 1968-not as a university building per se but as a replacement for the outpatient and other services of the Dunedin Hospital as part of a long-range redevelopment plan. Existing scattered services thereby came into this very necessary highly utilised facility. ${ }^{1}$

In the next paragraph Dr Hocken states: "In 1885 the Otago Medical School started a full medical course in Dunedin with graduation, MB ChB (New Zealand). This remained so until 1974, when Auckland Medical School graduated its first students and reversion to the designatory suffix of Otago was made." Anyone who has read Morrell's history of the University of Otago knows that the University 